UDC $1 / 14$

Tamás HANKOVSZKY

\title{
DAWKINS’ UNREBUTTABLE REFUTATION
}

\begin{abstract}
In the whole fourth chapter of The God Delusion Richard Dawkins in a long and complicated argumentation attempts to prove that God's existence is improbable and we have no reason to believe in Him. In my paper I am going to examine the basic structure of his train of thought first so that I present the detailed reconstruction of the single steps later on. Having scrutinized the reconstructed reasoning in the last section I am going to show that his main argument for atheism is unsuccessful.
\end{abstract}

Keywords: atheism, creationism, belief, probability, design, Darwinism, God, Dawkins.

\section{Introduction}

Richard Dawkins in the fourth chapter of the God Delusion presents an "unrebuttable refutation" to convert religious people to atheism. In the second part of my study (II) I show up the basic structure of Dawkins' argumentation and split his train of thought into four arguments building upon each other as follows. (1) "the ultimate Boeing 747 gambit" which argues that God as the allegedly explanatory being for terrestrial life is improbable; (2) the assumption of God as a designer leads to infinite regress; (3) the awareness of the fact that a theory implying such regress is untenable; in the end (4) presenting Darwinism as a more successful alternative to solve those problems that ultimately justify the acceptance of God-hypothesis according to some thinkers. In the third part of my study (III) I give the detailed reconstruction of this fourstep argumentation. In the fourth part (IV) I offer a critical examination of the reasoning following the single steps backwards. The paper ends with a short conclusion (V). Thus, first, in contrast to step four (4), I point out that although Dawkins claims that Darwinism holds out to offer an explanation for the phenomena of lifeless things better than design theory, it has not given that explanation yet; consequently, it cannot be regarded as real alternative for the explanation of the whole universe. Dawkins is certainly right in what he states in the third step (3). His atheist project, though, does not win anything with it since through scrutinizing the second step (2) of his reasoning I show that it is neither the traditional variants of theism or the argument for design that imply infinite regress, but the way how Dawkins reconstructs their point of view. Dawkins does not differentiate between terrestrial and other possible entities, thus between explanations concerning them. After the greater part of the atheist reasoning has proved to be untenable, I examine the first step (1) which seemingly stands on its own too. This argument is based on the thesis that the designer of complex things has to be even more 
complex. Thus, the reasoning ultimately relies on the generalization of the abilities of terrestrial designers and the characteristics of these designers' plans. This generalization is justified, though, only if we assume from the start that only one kind of intelligence can exist which is able to design. Dawkins here commits the same error which made the second step a case of petitio principii. Finally my conclusion is that Dawkins' refutation can indeed be refuted.

\section{The Basic Structure of the Argument}

The aim of The God Delusion is admittedly to convert its readers from religion (Dawkins, 2006, p. 116). Dawkins employs rather variable means to achieve this aim; nevertheless, he seems primarily to rely on the power of arguments. I am going to prove that his main argument for atheism is unsuccessful. This can only be confirmed by the careful investigation of what explicit and hidden premises of the argument are. If there are hidden premises, such a work is always difficult, and in the case of Dawkins we need to make considerable effort indeed, since the structure of his argumentation can only be revealed really hard. ${ }^{1}$

The argument can be found in the voluminous fourth chapter of the book (Dawkins, 2006, pp. 111-159) entitled Why There Almost Certainly Is No God? The section is preceded by a brief introduction at the end of the third chapter in which Dawkins claims that " $t]$ he

\footnotetext{
Often it is mentioned that the argument is so obscure. E.g. "This rambling pastiche is poorly structured, making it quite difficult to follow its basic argument" (McGrath \& McGrath, 2007, p. 27).

Some of the researchers considers the exposition of the argument confusing and ambiguous so much so it is necessary to reconstruct three potential interpretation of the main argument. Cf. Anglberger, Feldbacher \& Gugerell, 2010, p. 182 and p. 196.
}

whole argument turns on the familiar question Who made God?" (Dawkins, 2006, p. 109). As concluding the chapter and summarizing the train of thought there is a repetition in six points, out of which only the third point speaks explicitly about God in such a way that it reemphasizes the question of God's origin. After that Dawkins says "[i]f the argument of this chapter is accepted, the factual premise of religion - the God Hypothesis - is untenable. God almost certainly does not exist. This is the main conclusion of the book so far" (Dawkins, 2006, p. 158). It seems that reconstructing the argument we have to take the fact into consideration that the author has been led to his conclusion only by winding up the whole chapter rich in topics. Furthermore, the question concerning the infinite regress of who created the Creator also has role in the argumentation. This is important to be emphasized given that these factors may at first sight seem not to play any part in the argument. The chapter's first short subsection entitled The Ultimate Boeing 747 which does not deal either with the problem of God's origin or other topics of the chapter, seems to support an atheist conclusion on its own. Moreover, the author adds that "my name for the statistical demonstration that God almost certainly does not exist is the Ultimate Boeing 747 gambit" (Dawkins, 2006, p. 113). We could nearly think that Dawkins unconsciously expounds two independent arguments; though the fact makes us alert that he speaks about "the infinite regress of the Ultimate Boeing 747" on page 141. Thus the reasoning of the forth chapter seems to be cohesive in the author's intention. Therefore such an interpretation of Dawkins' reasoning is needed in which, on the one hand, the "gambit" has an important role so as to name the whole argumentation; on the other 
hand, the infinite regress and the chapter's other topics also add to the assertion of the atheist conclusion.

There is also a consideration which supports that the argument does not terminate in the gambit in Dawkins' intention. Not only at the beginning of the chapter, but also in the summarizing repetition we can find reference to an argument for God which proves God's existence on the basis of that the world seems to be designed. According to Dawkins, "it's easily today's most popular argument offered in favour of the existence of God" (Dawkins, 2006, p. 113). He also believes until this argument is not refuted, it stands in the way of atheism. The third chapter of the book which aims to refute arguments for God that are formulated in history so far, takes this argument in account, and claims that its refutation lies in Darwin's results so Dawkins "shall return to the argument from design in Chapter 4" (Dawkins, 2006, p. 79). Another section, though, considers the argument from design and its explaining Darwinist theory to be the central topic of Chapter 4, entitled Why There Almost Certainly is no God? (Dawkins, 2006, p. 73). The preface also emphasizes the argument from design and the Darwinist theory (Dawkins, 2006, p. 2). I suppose that in Dawkins' intention the answer for the question Why there almost certainly is no God? has to refute the argument from design as well and it has to refer to Darwin. However, the gambit alone does not fulfill either of them.

After all, this train of thought can be regarded quite complicated. The reconstruction has to consist of at least the four following elements. The gambit, the problem of regress, the refutation of design, and the reference to the evolution all have to be part of the reconstruction. Whoever would like to reject Dawkins' argument without using these elements for the reconstruction, Dawkins would easily say that the refutation is wrongheaded, since his reasoning was something else. No one from the analyzers and critics of The God delusion whom I have known presented Dawkins's argument as a complete reasoning in which all of these parts had the suitable role. In this paper I attempt to do this.

My own reconstruction is broadly the following. The first step (1) shows with the help of the Ultimate Boeing 747 gambit that if one correctly grasps the argument from design (or more exactly its one special variety, the creationist intelligent design theory), she should surprisingly arrive to the conclusion that God's existence as the explanation for life is improbable. The second and third step focuses on the intelligent design theory itself, and (2) shows that since God is improbable, its assumption leads to infinite regress within the frames of the theory. Furthermore it (3) draws attention to the fact that infinite regress makes the theory untenable, thus we can easily reject it altogether with the God Hypothesis. The last step (4) is the recognition that this theory can be rejected just because there is a more successful theory. Darwinism is able to solve the problem that was the main reason for creationist for supposing God's existence. $^{2}$ These steps underlie the conclusion that

\footnotetext{
2 According to Glass in the fourth chapter of The God Delusion Dawkins uses two sort of argument: one which corresponds with Hume's argument that was presented by Philo in Dialogues Concerning Natural Religion and another which refers to Darwin. In Glass' interpretation these two arguments are incompatible with each other. On the first hand the first three points of my reconstruction together could be corresponded to the Humean argument, on the other hand we can regard the fourth one as a soft version of the Darwinian argument supposed by Glass and which in this form could be compatible with the Humean argument. Cf. Glass, 2012, pp. 33-34.
} 
God is improbable and there is no reason for assuming that $\mathrm{He}$ does exist. And this means that it is very probable that God does not exist.

3. The Reconstruction of the Argument in Details

(1) The first step hence is the recognition of God's improbability. The "gambit" leads us to this recognition, which can be unfolded from two quotations. According to the first: "the probability of life originating on Earth is no greater than the chance that a hurricane, sweeping through a scrapyard, would have the luck to assemble a Boeing 747" (Dawkins, 2006, p. 113). Creationists - Dawkins' direct opponents - agree with this, therefore, they attribute life to God's designing activity. Notwithstanding that "however statistically improbable the entity you seek to explain by invoking a designer, the designer himself has got to be at least as improbable. God is the Ultimate Boeing 747" (Dawkins, 2006, p. 114).

It is apparent that a good opportunity straightaway presents itself for the atheist conclusion; God is so improbable that he almost certainly does not exist. This interpretation, however, cannot account for all the elements we have to regard as its components. In order to let these play a part later on, I reconstruct the train of thought hidden in the above two quotations with the following logical structure.

P1 Living creatures are improbable.

P2 Improbable things need explanation.

P3 Improbable things can be explained by a designer.

P4 The designer of improbable things has to be at least as improbable as the things that he designed.

C1 The alleged designer of living creatures
(God) is improbable.

Comments to the premises:

P1 - Creatures are improbable owing to their high complexity. The more components something consists of, the less the chance is that its components assemble just in the same way and not in another one as they factually assemble.

P2 - Everybody seems to agree with this premise who is unsatisfied with sheer facts.

P3 - This is one of the principles of intelligent design theory supported by the following simple argument. Since nothing can be explained by chance, complex beings cannot be explained other than as works of a designer. Dawkins as the opponent of this theory of course regards P3 premise false; moreover, he would be really interested in refuting it, therefore - it seems - he could not draw any conclusion from it. The fact that he does use it makes me infer that his argument is actually a form of reduction ad absurdum. Reduction ad absurdum refutes a premise or theory by proving that it leads to untenable conclusion. First he accepts certain premises then he examines what conclusion can be drawn from them: if something false or absurd is drawn, then one of the premises has to be false as well.

It seemingly excludes the above explanation of Dawkins' argument that in his opinion $\mathrm{C} 1$ is not false, moreover it is one of the principles of his whole atheist reasoning, therefore he cannot render P3 suspect either. It seems that P3 has to be true in order to be able to support the atheist conclusion. But if it is true, it is no purpose of thinking on the basis of $\mathrm{C} 1$ that the designer's existence is improbable, we do have to postulate God on the basis of P3. The problem does not arise, though, when we regard $\mathrm{C} 1$ just a transitional conclusion of a 
longer process of deduction and we expect the appearance of a result unsatisfying from the point of $\mathrm{P} 3$ only at the end of the process.

P4 - This is Dawkins' own premise. Even though he does not elaborate or justify it in details, it fits to his overall train of thought perfectly. Having examined P1 it has already been obvious that there is direct proportion between a being's complexity and its improbability. ${ }^{3}$ If we accept the unuttered premise - let us say P5 that the designer of a complex being has to be even more complex, then we have supported P4, since this even more complex designer certainly becomes more improbable. ${ }^{4}$ At least one of Dawkins' clearest claims is that God is complex. For instance once he says that "however little we know about God, the one thing we can be sure of is that he would have to be very very complex and presumably irreducibly so!" (Dawkins, 2006, p. 125). Elsewhere the complexity and improbability of God appears together "How do they cope with the argument that any God capable of designing a universe, carefully and foresightfully tuned to lead to our evolution, must be a supremely complex and improbable entity" (Dawkins, 2006, p. 147).

C1 seems to be really drawn from the above premises (and further trivial hidden premises), even though I have not elaborated on all the details of the process of deduction.

(2) The second step is the demonstration that intelligent design theory (and according to Dawkins all theism that regard life as the creation of God) leads to infinite regress. Having

3 For the Dawkinsian concept of probability, see: Anglberger, Feldbacher \& Gugerell, 2010, pp. 186188; and Glass, 2012, pp. 51-56.

4 Wieleberg explains the "substantive and crucial" P4 in this way as well (Wielenberg, 2009, p. 114). However he points out that "a weakness of his [Dawkins'] argument is that he doesn't provide much support for this crucial premise" (Wielenberg, 2009, p. 117). accepted the foregoing reasoning we can easily make sure of the truth of this claim. According to the above $\mathrm{C} 1$ conclusion God is improbable; therefore He himself needs explanation as well under P2. So we must begin a new process of deduction using the already familiar premises.

C1 God is improbable.

P2 Improbable things need explanation.

P3 Improbable things can be explained by a designer.

P4 The designer of improbable things has to be at least as improbable as the things that he designed.

C2 The alleged designer of God (God2) is improbable.

It is obvious that God2 due to his improbability again needs explanation, at the end of which we would be led to God3, for whose sake we should assume God4 and so on forth. Consequently, the acceptance of P1-P4 premises leads to infinite regress. If God were a necessary being, as traditional theology claims and not improbable "hypothesis", we would not need to offer explanation for his existence (Cf. Wielenberg, 2009, p. 118; Ganssle, 2008, p. 44; Plantinga, 2007, p. 3). The "gambit", however, has proved that $\mathrm{He}$ is improbable, moreover P2 needs explanation for his existence, though P3 can only accept the design as an explanation, it is inevitable that according to $\mathrm{P} 4$ at the conclusion we get to an entity at least as improbable as God.

That raises the question why we cannot stop at the regress as traditional thinkers did by supposing a designer who was not designed. And if we stop, the creationist could suggest not stopping by God2 or later, but right by God. Nevertheless if God was not designed, how does He come into existence? He cannot exist by chance, since chance is not an explanation 
for anything either for Dawkins or for the creationists. If we do not wish to explain the existence of the improbable designer further, however, no matter what traditional thinkers did, we will become unfaithful to our P2 premise, and it "is a total abdication of the responsibility to find an explanation. It is a dreadful exhibition of self-indulgent, thought-denying skyhookery" (Dawkins, 2006, p. 155).

(3) Dawkins in order to be able to examine P3, the thesis of the intelligent design theory, he accepted it to be true, but it turned out to lead to nowhere. We vainly rely on this theory because it does not fulfill what it promised; it does not offer an explanation. This fact is sufficient enough to reject it. The explanation would require a certain point from which the explicandum could be deduced. If we find this point, however, only in the infinity, since we cannot trace the chain of reasoning back there, the theory does not offer firm basis, does not provide an explanation. We have no reason to accept such an explanation. Although its theses cannot be regarded false, we have no reason either to accept them to be true; in this case there is no reason to believe that God designed the world. In Dawkins' manner we can say that God might exist, but it is no point in believing in him on the basis of a theory leading to infinite regress.

(4) According to the foregoing reasoning it seems that we have to reject not only chance but also God as designer as the explanation for the high complexity of the world. Yet there has always been need for explanation, and we have been aware for ages that this need seems to authorize much. At the background of certain traditional God arguments the idea appears that there has to be an ultimate explanation for worldly phenomena (such as movement), and this fact authorizes us to suppose something (the unmoved mover), which we otherwise would have no reason to suppose. So it was logical from the point of Dawkins that he completed his argument with a fourth step. ${ }^{5}$ If we were not able to present an alternative explanation (instead of a designer) for the complexity, the legitimate claim for explanation would make it understandable or at least pardonable if someone could still believe in the designer in the light of the first three steps. Argumentation against the existence of God cannot be finished until we do not provide an alternative explanation for the undeniably improbable existence of complexity found in the world which would make the assumption of a designer unnecessary.

Dawkins proposes the natural selection of Darwinist theory as the explanation for the high complexity of beings. Although he is aware of the fact that in the world there are such complexities for which there has been no Darwinist scientific explanation yet. How can we explain for example that the figures of different constants in natural laws relate to one another in such a way so that they enable the existence of the universe? The believer, even if he accepts that the complexity of beings can be explained by evolution, might be inclined to attribute the order of the universe to God's designing activity, not having other alternative. Dawkins thus has to give plausible alternative explanation for all the allegedly designed phenomena in the world. This is not an easy task, since he himself thinks that "it comes from natural selection: the process which, as far as we know, is the only process ultimately capable of generating com-

\footnotetext{
Sober remarks "Philosophers who believe that theories can't be rejected until a better theory is developed to take its place often sympathize" with the concept that Darwin's theory was the main strike against the design argument. Sober mentioned Dawkins as an example of such philosophers (Sober, 2004, p. 132).
} 
plexity out of simplicity" (Dawkins, 2006, pp. 150-151). Consequently, he tries an argumentation in two steps. On the one hand, he expresses his conviction that scientific interpretation similar to biological evolution is possible to be found on other scientific fields as well. "Natural selection not only explains the whole of life; it also raises our consciousness to the power of science to explain how organized complexity can emerge from simple beginnings without any deliberate guidance. A full understanding of natural selection encourages us to move boldly into other fields" (Dawkins, 2006, p. 116). On the other hand, until the desired scientific results are produced on other fields, we can rely on the united power of the so-called multiverse hypothesis and the anthropic principle. This way we cannot explain, though, how our universe as the harmonious cooperation of many factors came into being and subsisted, but at least it can be verified without the existence of God that the existence of the universe despite all the pretences is reassuringly probable.

Thus we have "an unrebuttable refutation" (Dawkins, 2006, p. 157) as Dawkins calls his argument. We have arrived to the conclusion that God is improbable and we have no reason to believe in him. The strongest God argument has failed, because science has shown that the allegedly designed beings can be explained without God. - Why should we believe in him, then?

\section{Is the Argument Successful?}

In the following I am going to show, that the argument is unsuccessful, so we do not have to accept its conclusion at all. Let us suppose for a moment that Dawkins is right, and it is almost improbable that God does not exist! This fact itself would not lead to conversion from religion, either. Moreover, we could even have rational reason for religion, to which we could be persuaded by an argument similar to Pascal's bet. No matter how small the probability that God exists and thus exists as Christian theology claims, we have to take this little chance very seriously when a so important matter is at stake whether I shall say yes to God or not. The situation is somewhat similar to when we think that everybody has the right to the presumption of innocence even despite reasonable suspicion. No matter how evidential arguments are taken contra someone, no matter how probable that he is guilty, the stake of prejudiciary is so great, namely the possible hurt of the person's dignity that we cannot take risk. Whoever understands what 'person' means, will never say that the presumption of innocence could be an irrational attitude. Nevertheless, if the matter at stake is even greater, that is, infinitely great as in the case of God, then it is indeed rational to believe in it even if someone proves that the probability of God's existence is infinitesimally small. Dawkins might be right when he thinks in his Pascal-critique (Dawkins, 2006, pp. 103-105) that reason in itself can never lead to God, and the relation, in which we can relate to him only via calculative reasoning, would mean nothing. Would it be proper, though, if we convert from God by listening only to the voice of reason as Dawkins expects us to do so working on our "conversion"? Would it be reasonable to doubt particularly having considered all of its own weight if reason itself cannot offer us to doubt, if at least reason can accept if there is God, then it has high value not to turn our back on God?

Atheism does not follow even from Dawkins' conclusion thus. However, following the steps of the reconstructed reasoning backwards, it can be demonstrated that the conclusion itself 
is unfounded.

(4) Even if we accept that biological evolution gives satisfactory evidence for the facts and modi operandi of high complexity, thus for improbable phenomena in the world, and even if we are convinced that science will by and by present similar results in its other fields too, we cannot consider it as to have happened already. From this perspective anthropic principle counts for little, since - even if we accept the multiverse hypothesis fitting to sci-fi literature ${ }^{6}-$ it only shows that universe similar to ours is not at all improbable, although it does not explain how it came into existence and can subsist. But if we know only that one thing happened without knowing why and how it happened, for someone who would like to get answers to these questions in the absence of scientific explanation there is no other choice than to refer to a designer. Until we do not have a plausible scientific answer for example for the universe's complexity too, theories referring to God at least are not unnecessary, therefore the "Godhypothesis" itself is not unnecessary, either. Irrespectively of what we think of the belief which can be endangered by scientific progress, one thing is sure that future possible results can at present be neglected.

(2) If we take the third step for granted, namely we accept that each theory leading to regress can be rejected, at the second scrutiny it is worth examining whether intelligent design theory (as well as traditional forms of theism and the argument from design) really leads to regress or not. More precisely, it is being worth examining whether really intelligent design is responsible for the regress or not. Dawkins all

6 To the criticism of the anthropic principle and the argument referred to the multiverse theory see Plantinga, 2007, p. 4. intents and purposes thinks so. On page 121 he claims that the key of the theory - the idea of design - leads to regress. Another reference locates even more precisely the spring of regress. The introductory words of Chapter 4 are the following: "God presents an infinite regress from which he cannot help us to escape" (Dawkins, 2006, p. 109). This will be apparent from the next quotation when we recall one of the main points of Dawkins' Thomas Aquinascritique: "they make the entirely unwarranted assumption that God himself is immune to the regress" (Dawkins, 2006, p. 77). When Dawkins learns that infinite regress is concluded from a set of premises, in which P3, the basic principle of intelligent design theory is also contained, he expects hardly other than the premise of intelligent design is responsible for the undesired result. And if it is so, that very premise has to be rejected as well as of course the theory representing it. Except that Dawkins expressed his opinion well before about God's concept containing regress, we have no other reason to blame this premise. Dawkins here makes the logical error called petitio principii. He would like to deduce that the intelligent design theory contains regress; however, he draws this conclusion from what he has already assumed namely that the basic principle of the theory contains infinite regress. If he did not suppose that, he could look for the spring of regress in P4 instead, owing to which $\mathrm{C} 1$ and further conclusions result in improbable beings, rather than in P2 according to which what is improbable should be explained. I am going to deal with P4 later and we will see we have no reason to consider it to be true; moreover, it is very plausible that the unacceptable result of the inferential chain somehow relates to it. At least is P2 true? We have seen that Dawkins accuses all of "self- 
indulgency and thought-denying skyhookery" who are unwilling to give explanation for all the improbable things. For this, the creationist could rightly answer that just the one does have problems with his or her self-evaluation who thinks he can give explanation for everything, even for God. Until this debate is not settled, it is not clear whether P2 is acceptable or not. Even if $\mathrm{P} 2$ and $\mathrm{P} 4$, though, turned out to be correct, thus we should consider $\mathrm{P} 3$ to be the spring of regress that would not show either that the intelligent design theory would be false. Perhaps Dawkins gratuitously phrases P3 too sharply. Why could not creationists phrase their own argument different from that of Dawkins:

Improbable terrestrial things can be explained by a designer? Thus regress would not appear. Dawkins himself seems to have encoded error into the intelligent design theory, because he was not able to make difference between terrestrial and other possible entities, thus among explanations referring to them. (Of course I have not proved that creationism is a true or at least plausible theory, I only showed that creationism has not been refuted by Dawkins).

(1) If someone accepts the above counterargument, he or she can still hope that at least the very first step of the reasoning, namely the "gambit" is true. Putting aside the steps (2)-(4) which seemed to be faulty in the light of the above investigations, the "gambit" can be phrased simpler than above. Having wondered the miracle of life, the creationists have come up with the concept of God. We need to accept none of their theses in order to be able to examine by conceptual analysis what a designer should be like to explain the phenomena of life through him. According to the analysis he should exist with even smaller probability than life which should be explained. Such conceptual analysis, though, would use the above $\mathrm{P} 4$ thesis (The designer of improbable things has got to be at least as improbable). So no matter how we reconstruct the logic of the "gambit", its persuasive power stands on the truth of P4. However, there are good reasons to doubt in P4.

It has been apparent before that we can argue for P4 on the basis of P5 according to which the designer of improbable things has to be at least as improbable as the things that he designed. If we wish to regard God as the designer of complex things, we have to admit that he himself is complex as well. ${ }^{7}$ However, traditional theology and philosophy definitely claims that God is simple. ${ }^{8}$ This makes P5 susceptible.

We can rather argue for P5 mostly on the basis of the consideration that all the single particles of a designed thing have to be there on the level of both the plans and the planner. If, for example, all the windows of a building are planned, on the plan there cannot be seen fewer windows than in reality. ${ }^{9}$ The different parts of the plan must suppose differences in the planner, too, at least different activities how he has drawn the single elements. Nevertheless, that reasoning proceeds from the abilities of terrestrial planners, from the characteristics of manmade plans, and it generalizes these. Whoever states that every planning activity has to fit the same laws as we can see either in the case of men or that of the natural world, in terms of some monism, arbitrarily projects the known

7 The nature of the complexity in Dawkins' theory is not clear. Probably it is a physical one (Nagel, 2006, p. 26). However it is possible that "Dawkins means a complex mental structure - albeit a nonphysical one" (Ganssle, 2008, p. 41).

8 E.g. Aquinas, Summa Theologica, I, q.3, a.7. On the question see Wielenberg, 2009, pp. 121-126. Plantinga points out "given the definition of complexity Dawkins himself proposes, God is not complex" (Plantinga, 2007, p. 3).

9 To the criticism of the argument see Crean, 2007, pp. 14-17. 
laws to the whole known and unknown reality (cf. Crean, 2007, p. 14). The argument foregrounding the gambit is thus logically false, since it assumes from the start what the gambit itself would like to show, indeed even more. Not only does it attempt to show that God is improbable, but also that he does not exist at all. If we suppose that nothing exists of which activity could be different from that of men, then evidently God cannot exist, either. However, we seek answers just to the question whether a power exists exceeding mankind and their possibilities.

Anyway, Dawkins does not arbitrarily project the validity only of the unspecified laws regulating the plans' making, but also the laws of biological evolution to all possible reality. "Any creative intelligence, of sufficient complexity to design anything, comes into existence only as the end product of an extended process of gradual evolution." (Dawkins, 2006, p. 31). If God existed, he should be a slowly evolved matter, or even biological reality. In the sense defined, though, God has no beginning and he is not material. Dawkins' conclusion comes natural: "God, in the sense defined, is a delusion; and, as later chapters will show, a pernicious delusion." (Dawkins, 2006, p. 31) This is even a stronger statement than saying he surely does not exist.

Consequently, P5 is supported by that default assumption that only one kind of intelligence can exist who is able to design. We do not need to accept this, even if we cannot show that other kind would really exist. We have to accept, then, neither P4 following from P5, ${ }^{10}$ nor the "gambit" based on them, from which

10 McGrath \& McGrath (2007) override P4 in another way: they doubt that it is necessary to regard improbable a thing which is complex. Cf. McGrath \& McGrath, 2007, p. 28.
Dawkins drew the conclusion of God's improbability. $^{11}$

\section{Conclusion}

The soundness of an argument depends on two factors. On the one hand, it depends on the correct inference; on the other hand, on the truth of those premises on which its conclusion is based. In Dawkins' atheist reasoning, however, we can find both severe logical faults and implausible premises even if we are able to reconstruct the assertions of The God delusion as parts of a single argument. We can consider it to be refuted.

\section{REFERENCES}

Anglberger, A. J. J., Feldbacher, Ch. J., \& Gugerell, S. H. (2010). Richard Dawkins Hauptargument wissenschaftstheoretisch betrachtet. In A. J. J. Anglberger, \& P. Weingartner (Eds.), Neuer Atheismus wissenschaftich betrachtet (pp. 181-198). Frankfurt, M. - Paris Lancaster - New Brunswick, NJ: Ontos-Verlag.

Aquinas, Th. (1947). Summa Theologica. New York: Benziger Brothers, 1947. Retrieved May 28, 2018, from: https://dhspriory.org/thomas/summa.

Crean, R. (2007). God is No Delusion: A Refutation of Richard Dawkins. Fort Collins, CO: Ignatius Press.

Dawkins, R. (2006). The God Delusion. Boston - New York: Houghton Mifflin Company.

11 Adding to this, if we reject or at least doubt in P4, it serves new basis for not to blame P3 for the infinite regress. The untenable conclusion might have appeared due to $\mathrm{P} 4$, too. 
Ganssle, G. (2008). Dawkins's Best Argument: The Case against God in the God Delusion. Philosophia Christi, 10(1), 39-56.

Glass, D. H. (2012). Darwin, Design and Dawkins' Dilemma. Sophia, 51(1), 31-57.

McGrath, A., \& McGrath, J. C. (2007). The Dawkins Delusion? Atheist Fundamentalism and the Denial of the Divine. Downers Grove, IL: Intervarsity Press.

Nagel, Th. (2006, October). The Fear of Religion. The New Republic, 23, 25-29.
Plantinga, A. (2007). The Dawkins Confusion. Books and Culture, XIII(2), 21-24. Retrieved May 28, 2018, from: https://www.booksandculture.com/arti cles/2007/marapr/1.21.html 1-6.

Sober, E. (2004). The design argument. In W. Mann (Ed.), The Blackwell companion to the philosophy of religion (pp. 117147). Oxford: Blackwell.

Wielenberg, E. (2009). Dawkins's Gambit, Hume's Aroma, and God's Simplicity. Philosophia Christi, 11(1), 111-125. 